\title{
LVII. Case of hydrophobia cured in India by bleeding
}

\section{John Shoolbred M.D.}

To cite this article: John Shoolbred M.D. (1813) LVII. Case of hydrophobia cured in India by bleeding, Philosophical Magazine Series 1, 41:181, 358-365, DOI: 10.1080/14786441308638763

To link to this article: http://dx.doi.org/10.1080/14786441308638763

曲 Published online: 27 Jul 2009.

Submit your article to this journal $\asymp$

Џ Article views: 2

Q View related articles $\asymp$ 


\section{$\left[\begin{array}{ll}355 & ]\end{array}\right.$}

LVII. Case of Hydrophilia rured in lndia by Bleeding,

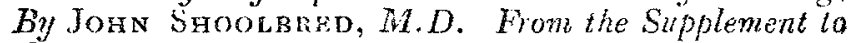
the Calcutta Government Gavette, June 5, $1812 *$

Tuesday, May 5, 1812.-A Bour 3 P.M. Ameir, a Muselman Bhestie, from 25 to 30 ycars of age, and middle stature, in the service of Mr. John Wod, schoolmaster, at Chowringhee, was brought to the Native Hospital, labouring under the most mequivocal sytmptoms of hydrophobia.

The note from $\mathrm{Mr}$. Wood, renuesting admission for this patient, and the friends who accomranied him, stated that he had been hitten in the leg about three wetes before, by a dog believed to be mad, and that the symptoms of his disease had appeared that morning, the 5th.

I visited him in the kospital, the moment I heard of his arrival, and found him sitting on the side of a cot, with an attendant bolding hin by each arm. The fist view was sufficient to satisty me of the nature of his complaint. His body, arms, and throat were affected with constant and uncontrolable spasmodic startings. The muscles were thrown into quick convulsive action at cach inspiration, drawing back the angles of the mouth, and at the same instant depressing the lower jaw, so as to communicate the most hideous expression to the conntenance. His eves appeared starting from their sockets and suffuser with blood; sometimes fixed in a wild and terrific stare; at others, rolling about, as if they followed some ideal object of terror, from which he apprebended immediate danger. A riscid saliva flowed from his moth, which was always open, except when the lips wore momentarily bronght togeties for the purpose of forcibly expelling the offersive secretion that adbered to them, and which he effected with that peculiar kind of noise, which has been often compared to the barking of a dog. His temples and throat were hedoned with clammy moisture. His respiration inas excedingly hurred, and might more properly ise called panding than bicathing; or, it still mure nearly resmbled that siont and uninterrupted kint of sobbing, that takes fiace when a person gradually descends into the cold bath. He was excectingly impaticnt of restraint, and whenever he could get a hand disengaged, he immeditely strick the pit of his stomach with it-pointing out lint par: as the scat of some undescribable uneasiness. From the constant dgitation of his whole frame and the startings of his armis, it was impossible

* Our readers will recollect that a few nonths ago we briefly noticed this temarkable case.-IDET. 
to count his pulse with exactness; it was, however, very uncqual, both in strength and frequency; at times scarcely perceptible, and then rising again under the finger; sometimes moderately slow and reguiar for a few pulsations, and in mediately after, so quick as not to be comted; but conveying, upon the whole, an icina of a greatly oppressed and impeded circulation. His skin was not hot; and though his bead was in incessant motion, accompanied with such savage expression and cuntortion of countenance as might easily have alarmed those unaccustomed to such appearances, he made no attempt to bite; wbich is far from being a frequent symptom of the disease, and, when it does occur, must be considered merely as an act of impatience at being hetd-and no more than the peculiar noise above noticed, as indicating any thing of the canine nature imparted by the bite, an opinion which has been sometimes fancifully but absurdly entertained.

When questioned concerning his own feelings, or the cause of his illness, he was incapable of making any reply; being prevented, it is probable, either by the hurried state of his respiration, or by his mind being too deeply absorbed in the contemplation of horrible ideas, to admit of his attending to the queries addressed to him.

I desired water to be offered to him; at the mention of which he started with increased horror and agitation, and endeavoured to disengage himself from those that held him. When one of the attendants approached with a cup of water, he looked at it wishfully, and after some efforts, with apparent reluctance, stretched out his hand to take hold of it; but before he could reach the cup, his hand was suddenly drawn back by a convulsive motion : at the same instant he turned away his bead, and writhed himself round on the bed in an agony of terror and despair, wholly inconceivable by any person who has not been a witness of the horrors of this most dreadful, and bitherto, it may be added, most irremediable of human maladies.

Such $w$ as the state of the patient at the moinent of his admission, and for the few minutes that necessarily elapsed while these appearances were passing under my observation.

Of the nature of the complaint there could not exist a shadow of doubt; and having so recently read in the Madras papers a case of hydrophobia successfully treated by Mr. Tymon, of His Majesty's eqd dragnons, by bleed. ing, mercury, and opium, I determined on the immediate adoption of the same plan. 


\section{Case of Hydropholia cured in India by Bleeding.}

I therefore without delay opened a vein in the right arm by a large orifice, out of which the blood sprung with uncommon impetuosity, and of so florid a colour as to resemble arterial rather than venous blood. By the time that sixteen or twenty nunces of blood had flowed, the spasmodic startings of his arms, body, and neck had considerably diminisherl, his breathing had become more calm, with less contortion of countenance, and he audibly acknowledged that the pain about the pracordia and region of the stomach was upon the decline. Encouraged by these incipient appearances of amendment, I allowed the flow of blood to continue; and when about two pins were taken away, seeing him greatly composed, I desired water to be again offered to him-when, cqually to wy astonishment and delight, he took the cup in his left hand, the blood still flowing from the right arm, and calmly - but w ith indescribable expression of satisfaction, drank two or three ounces of water-the sight of which but a few minutes before had thrown him into the most dreadful agonies. Soon after swallowing the water, be retched three or four times, but ejected nothing but saliva from his mouth and fauces; and finding now that his pulse was 104 , weak, soft, and regular; that he was become faint, and that all appearance of uneasiness had ceased, so as to allow him to take a second draught of water, about four ounces, I closed the vein and laid him down on the bed. At this moment he expressed a desire to have a natoral alvine evacuation, and wished to go out of the hospital for that purpose; but as that could not be complied with, he took no more notice of it at this time. It is woriby of remark also, that during the bleeding he made a sign to have himself fanned, a thing I never knew a hydrophobic patient to do before;-their distress being so uniformly increased by any current of air blowing upon them, that, according to all my experience, the dread of air in motion is as constant an attendant on the disease as the diead of water itself.

After the bleeding he remained perfectly quiet, and fell into a slumber for about an hour;-another circumstance which also strongly marks the abolition of the disease, as no hydrophobic patient was ever known to sleep. When lie arioke, he expressed a wish to have some sherbet; which was immediately given to him, and he drank four ounces of it with purfect ease. He then fell into another slumber, during which some convulswe startings were again perceptible about his arms, chert, and face, but not strong enough to wake him. At a quarter past five he spontane- 
ously awoke, and appeared again somewhat agitated, witis more suspicion in his looks, and of apparent doubt whether he could swallow as well as before; for when be took the. rup, he pat it to his lips with a quick motion, and gulped down about four ounces of water in a hurried manner, as if afraid that the difficulty of swallowing would be increased by a moment's delay. He also put his hand to the region of the stomach, and said that the pain in that part was returning. These threatenuge appenrances of relapse determined me to hazard a furmer detraction of blood. I therefure immediately opened a vein in the leit arm, and allowed the bloud to flow again till he completely fainted; but previously to this effect of the bleeding, the pain at the siomach had ceased; and while the blood was yet flowing be had again drunk four ounces of water without fear or disgust. When he recovered from the fainting fit, he retched several times, but, as before, discharged nothing but saliva.

At the end of the first bleeding his pulse was 104 ; immediately before the second, it was 96 , with a slight degree of sharpness in the beat; and after recovering from the fainting occasioned by the second bleeding, it was 88 , regular, soft, and feeble, and he now complained of nothing but extreme weakness, and giddiness of the head. And at this stage of the case, I apprehend, it will be allowed that the cure of the hydrophobia was completewhether it would be permanent or not, remained yet to be scen.

Whe1 I began the treatment of this patient, it was my intention, as $\bar{j}$ have said, to follow in every circumstance the practice pursued in Mr. Tymon's successful case ; and accordingly, a draught with 100 drops of tincture of opium, and an enema of 300 , were in readiness to be administered immediately after the hleeding. But seeing the surprising effects of the bleeding alone, and feeling convinced that the disease was, for the present at least, completely annihilated by the copiousness of that evacuation, I determined to preserve the treatment as simple as possible, in order that, if the patient did finally recover, it might with certainty be known to what he owed his safety; and that thence the application of the same practice to future cases of hydrophobia might with the greater confidence be recommended:-a resolution in which 1 was the more confirmed, from having heard some medical friends, whose opinions are entitled to every degree of respect, ascribe $\mathrm{Mr}$. Tymon's success to the mercury he had used, rather than to the bleeding. 
I am now fully persuaded, however, that I might safely, as far as the hydrophobia was concerned, have, omitted all remedies after the bleeding; but thinking that calomel and opium in repeated doses were more likely than any thing else, to induce that state of the system which would be least favourable to a relapse; and also that if the patient, notwithstanding his present promising appearance, did not finally recover, it would certainly be said that $I$ bad not given him a fair chance, by departing in any particular from the treatmont which had proved so successful in the hands of Mr. Tymon, I was inclined to conform to it so far, as to order four grains of calomel and one grain of opium to be given every three hours.

The first pill was taken at a quarter before six ; but it was immediately rejected, followed by some water. A second was given five minutes before six, and remained. He now slept till seven-then drank some more water, and had a natural evacuation of his bowels;-another circumstance which confirmed me in the belief that the disease was completely and permanently subdued-having never before seen in my own experience, nor read in any history of the disease, of such an occurrence as a natural action of the alimentary canal in a case of hydrophobia.

At nine he took another pill, and again at twelve-and continued to slumber and drink water as often as he pleased.

Wednesday, May 6th-(2d day) six A.M. Has passed the night well. Took a pill at three, and another now. Has drunk water frequently. Pulse 84. Skin cool. Tongue clean at the edges-some remains of betel, eaten before he was taken ill, covered the centre part. Two more alvine evacuations during the night. Complains of head-achebut is entirely free from uneasiness about the stomach.

On examining the blood drawn yesterday, it is found not to be in the least convex - neither does it exhibit the slightest nppearance of what is called the buffy coat. The quantity first drawn, making allowance for the evaporation of the night, measures 40 ounces; and the last between seven and eight.

Nine A.M.-Took another pill, which was followed by another evacuation; and in half an hour afterwards he ate eight ounces of sago. Is quite composed, and cau an. swer questions distinctly concerning the accident and subsequent occurrences, till the time he was taken ill.

He says that 19 days ago (including this day) when returning about four in the afternoon, from his own house at 
Russapuglah, to his master's at Chowringlee, he saw a pariah dog seize a fisherman, and bite him. Several people were collected at the spot-he also approached, when the same dog ran at him, and as he was retreating before him, bit him in the back part of the right leg, about six inches above the ankle, where he shows two scars at the distance of an inch and a half from each other, but without any appearance of inflammation or thickening of the integuments. The dog, after biting him, disappeared, and he does not know what became of him or of the fisherman. The wounds blerl a good deal; but not being very deep, they soon healed without any application. He took no remedy, except, on the day he was bitten, a small piece of scarlet cloth (sooltanee banat) wrapt up in a piece of ripe plantain, which was recommended to him as an infallible antidote against infection from the bite of a mad dog. He never saw any one in hydrophobia; and though he had heard that persons bitten by a mad dog were iiable to such a disease, the apprehension of it never dwelt on his mind, or scarcely ever occurred to him after the day on which he was bitten. He continued in his usual health till the 4 th instant, seven. teen days after the bite, when be found himself dull, heavy, and listless, with loss of appetite and frequent apprehension that dogs, cats, and jackalls were about to seize upon him. He also felt a pricking sensation in the part bitten. When his mother-in-law brought him his breakfast, he was afraid to eat it. He continued his busmess, however, of taking water from the tank to the house, till about noon of that day, after which he conld not bear to look on or to touch the water, being constantly barassed, whenever he attempted to do so, with the horible appearance of different animals ready to devour him. He now, for the first time, thought of the disease arising from the hite of a mad dog, was convinced that was the rause of his present distress, and fully believed that he should die of it. He ate no supper, nor drank any water that night, in consequence of the horrible phantoms that incessantly haunted his imagination. In the morning, all his horrors were increased, the spasms came on, accompanied by anxiety, oppression, and pain about the pracordia and stomacts; and those about him say that he contimued to get worse in every respect, until he arrived at the hospital in the state already described. He does not himself distinctly remember any thing that happened during the whole day. He has some faint recolJection of having been at his own house; but how he got there-when he left it - or by what means he was brought 


\section{Case of Hydrophobia cured in India ly Bleeding.}

to the hospital, he does not at all know. The first thing he can recall. to his mind is drinking the sherbet-and he says he has had his senses perfectly since that time-and that all his fears then left him, and have not since returned. This however is not entirely correct, as he acknowledges that he does not recollect the second bleeding, which shows that the disease had then so far returned as again to disorder his mental faculties.

Half past ten A.M.-Complains of severe head-ache, and his eyes are more suffused than they were in the morning. No return of other symptoms.

Head shaved, and six leeches applied to each temple.

Three P.M.--Took a pill at twelve, and another just now. Leeches bled freely. Head-ache relieved. Took eight ounces more of sago about noon.

Six P.M. - The same. Has now taken 28 grs. of calomel and seven of opium. To take from this time only two grs. of calomel and half a grain of opium every three hours.

Nine P.M.-Has slept for two hours. Pulse 80. Took another of the pills last ordered; also some more sago. Copious bilious evacuation. Still complains of giddiness, but not head-arhe.

Thursday, the 7 th, (3d day,) six A.M.-Took a pill at twelve, but refused one at three, saying his mouth was sore. Tock one now. Has been rather restless in the night. Threw up some bile this morning.

Ten A.M.--Exceedingly distressed with excessive secretion of bile, which he is frequently throwing up and also passing downwards in great quantity; and of a dark green colour. Pulse 110. Some heat of skin-expression of uneasiness in his countenance-burning sensation all over the abdomen; but quite different, he says, from the former pain about the stomach. He was ordered a pint of infusion of camomile, which brought off much bile. At eleven, eight grains of calomel, and at half past twelve, half a dram each of jalap and magnesia. From the effects of these remedies, he was much relieved in the evening; though the complaint continued to disturb him in the night, and it was necessary on

Friday morning the 8 th, (4th day,) to promote the further evacuation of bile by senna, manna, and cream of tartar ; and to order an enema of conjee to allay local irritation. Pulse only $80,60 \mathrm{ft}$. Burning removed from the abdomen. Ate a water melon in the night. Copious flow of saliva from his mouth.

Saturday 9th, (5th day,) nine A.M.-Has passed a good night. 
night. Excessive secretion of bile has crased. Clamorous for fnod-but $I$ allow him only rice and sago-declines milk. He appears now to be free from all complaint. After this time nothing remarkable occurred. Hie had a strong appetite, and was allowed vegretable curry. For several evenings some heat of skin aad acceleration of pulse were perceptible; but these soon went off, from cold bathing and a constant attention to keep lis bowels in an open state.

Monday, May, 18th, (14th day.) - Has been for some days past on the usual hospital diet-anci fecing himself well in every respect, now expresses a wish to be lischarged and return to his usual business; but as the weather is exceedingly hot (thermomeler in the shade from $95^{\circ}$ to $100^{\circ}$ ), I have prevailed upon him to continue in the hospital till the setting in of the rains. - I shall then, if possible, persuade him to remain in my own employment for the next twelve months; lest, if he were discharged, and should happen to die of whatever disease, it might be alleged that he was after all carried off by a relapse of the hydrophobia.

[To be continued.]

LVIII. Notices respecting New Books.

Elements of Crystallography, after the Method of Haur, with or without a Series of geometrical Nodels, inth solid and dissected, exhiliting the Forms of Crystals, their geometrical Structure, Dissections, and general Lau's according to which the immense Variety of actually $e x$ isting Crystals are produced. By FREDRICK ACCUM, Operative Chemist, Lecturer on Practical Chemistry, छैc. M.R. I.A., E. L.S. \& c. pp. Ixiv. and $306,8 v 0$. with four Plates. Longman and Co. 1813.

The author has very laudably cndeavoured to render the diffeult subject of crystallegraphy fitmiliar to persons unacquainted with geometry. The task was somewhat ar. duous; but those who canont comprehend bis figures and descriptions, may have recourse to his models, which supersede the necessity of mathematical knowledge. His nodels amount to fifty, his figures to 103 , "which embrace nearly all the different forms of crystalline bodies. As crystallography is rather a new science, the necessity of elementary or introductory treatises on it must be obvious. Hitherto nothing of the hind has appeared either in France 